\section{Reprints still in demand}

SIR-Following on the discussion on reprints (Nature 336, 708; 1988) I should like to raise two points that very much concern a minority of workers like myself.

First, as a full-time school teacher who has a reasonable output of papers and whose place of employment is not in a university or professional laboratory, I rely on reprints to keep me abreast of my subject. To start with, I rely on a small nucleus of workers who automatically send me reprints of relevant papers. From those. I can then follow up what seem to be useful references by sending for more reprints. I do not have access to abstracting systems nor to libraries that stock journals except on the rare occasions when I make the journey to London.

Second, as an isolated entomologist, I become aware of others with an interest in my field only by receiving reprint requests.

I would be very sad indeed if Ivor Smith's attitude started a widespread movement away from the reprint system.

The Common Room,

Uppingham School,

Uppingham,

Rutland LE15 9QE, UK

SIR-Ivor Smith expresses his discontent about the reprint requests he received for his two-page paper, all of which he ignored. He claims that "the European reprint is a disappearing commodity". I believe this attitude is detrimental to at lcast one part of the scientific community and is inconsistent with efforts to improve cooperation and exchange of information between scientists in the West and East (Nature 337, 1; 1989).

I have recently received 153 requests for a one-page paper, 90 of them from countries where neither photocopiers nor scienfific journals are abundant. I myself worked for five years in an institute of the Czechoslovak Academy of Sciences. The institute was well equipped and financed and theoretically one could get any paper, but it could take weeks or months, depending on the availablity of the journal. It was not possible to order all the papers one wanted that were not available in the library - the capacity of the service would have been far exceeded. Bureaucracy and censorship made things even more complicated: for example, issues of Nature were sometimes incomplete. One had to order a copy of a specified article and sign a declaration that the copy would be used only for scientific purposes. Such measures will vanish with the general political shift, but the availability of the scientific literature will not improve significantly in the near future. Reprints remain an important source of information for researchers in the Eastern bloc.
Ivor Smith uses the difference between the cost of postage and that of a photocopy as an argument against reprints. Such reasoning is inappropriate for scientists in the Eastern bloc: as money for postage is limited, some workers pay for this service themselves. This is necessary especially in fast-evolving fields or where more than one field has to be pursued simultaneously.

The decision whether or not to answer a request is a personal one. It depends also on postal funds available. Nevertheless, there is a consensus in the scientific community that reprint requests should be answered. Not to do so is unfair to those who conform - journals that provide authors with free reprints and researchers who ask for them. I suggest, therefore, that authors who cannot or do not intend to send out reprints make an arrangement to spare others the unnecessary costs: as a part of the corresponding address (in order to be included in indexing periodicals such as Current Contents), a note "no reprints" should be inserted. This could also serve as a hint for the journals in question to save the costs of producing free reprints.

PETR KaRLovsky Abteilung für Molekulare Genetik (GSF), Grisebachstrasse 6,

\section{D-3400 Göttingen, FRG}

SIR-If one wants a copy of a recent paper that has photographs showing ultrastructural detail (common in microscopy and biology journals), then a photocopy is usually not good enough.

\section{Department of Paper Science,}

University of Manchester Institute of Science and Technology,

\section{PO Box 88,}

Manchester M60 1QD, UK

\section{Sadly confused}

SIR-Frank W. Dobbs' criticism, (Nature 337, 497; 1989) is sadly correct, as you noted, but he is sadly mistaken on who was confused: it was Kepler who analysed Tycho's measurements and not Copernicus who analysed Kepler's - to wit: Copernicus 1473-1543, Tycho 1546-1601. Kepler 1571-1630.

KLAus SANDER

Albert-Ludwigs-Universität, Institut für Biologie I (Zoologie),

Albertstrasse 21 a,

D-7800 Freiburg,

FRG

Letters submitted for Correspondence should be typed, double-spaced, on one side of the paper only.
African birds

SiR-Tim Crowe's diatribe (Nature 338, $11-12 ; 1989)$ on the seventh Pan-African Ornithological Congress (PAOC) left me wondering if we had actually attended the same event. I did not think I was alone in finding it a highly enjoyable, well-organized and scientifically stimulating conference which could also (for the first time, it seems) honestly be described as 'panAfrican' in its representation.

It is possible to understand Crowe's frustration over the processing of his and his colleagues' visas. But his obsession with the so-called 'exclusion' of South Africans prevents him from grasping the fact that the future of African ornithology depends on our building a basis for it over the entire continent. In this regard, his dismissal of the papers given by African delegates is particularly unhelpful (not to say offensive). Unfortunately, few African ornithologists will have had access to resources and training of the calibre provided by a FitzPatrick Institute. This makes it all the more important that young scientists have the chance to attend international conferences such as this one, where they can present work, receive constructive criticism and learn from the example of their more experienced colleagues. Indeed, this is one of the best reasons for the congress's new regionalism. The fact that last year's meeting was held in East Africa allowed many scientists to attend who would otherwise never have had the chance, and at future congresses this opportunity will be extended to those in Central and West Africa as well.

Crowe's nostalgia for the days when the PAOC was run by South Africans for South Africans is profoundly unrealistic. I doubt that the absence of many distinguished South African ornithologists can have cheered any delegate to the seventh congress, even among the supposedly "virulent anti-South African elements". But this situation clearly arose as a result of the distortions induced by apartheid. distortions which, while they act to impoverish African science, cannot simply be ignored. The cost of guaranteeing South African participation in all future congresses would be the continued paralysis of pan-African ornithology, and the seventh PAOC decided that this cost is too great. Eventually, the isolation of South African ornithologists must be ended through political change. In preparation. Crowe's colleagues would do well to follow the positive steps outlined at the end of his article - in particular to remedy the disgraceful lack of black South Africans among their number.

Edward Grey Institute of Field Ornithology, Department of Zoology,

University of Oxford,

Oxford OX1 3PS. UK 